https://helda.helsinki.fi

Complexity and Organizational Communication : A Quest for Common Ground

\title{
Poutanen, Petro
}

2016-06

Poutanen , P , Siira , K \& Aula , P 2016 , ' Complexity and Organizational Communication : A Quest for Common Ground ' , Human Resource Development Review , vol. 15 , no. 2 , pp. 182-207 . https://doi.org/10.1177/1534484316639713

http://hdl.handle.net/10138/173366

https://doi.org/10.1177/1534484316639713

acceptedVersion

Downloaded from Helda, University of Helsinki institutional repository.

This is an electronic reprint of the original article.

This reprint may differ from the original in pagination and typographic detail.

Please cite the original version. 
Complexity and Organizational Communication: A Quest for Common Ground

$$
\text { Petro Poutanen }{ }^{1 *}, \text { Kalle Siira }{ }^{2} \text {, Pekka Aula }{ }^{3}
$$

\author{
${ }^{1}$ University of Helsinki, Finland \\ ${ }^{2}$ Constra Group, Helsinki, Finland
}

${ }^{3}$ Finnish Academy of Science and Letters, Helsinki, Finland

This is the author's version of the published paper: Poutanen, P., Siira, K., \& Aula, P. (2016).

Complexity and Organizational Communication: A Quest for Common Ground. Human Resource Development Review, 15(2), 182-207. doi:10.1177/1534484316639713

*Corresponding author: petro.k.poutanen@gmail.com 


\begin{abstract}
In recent years, a growing body of literature has emerged from the intersection of complex systems science and organizational communication. However, due to the incoherence and immaturity of complexity science, this body of research is slightly disorganized. This article explores this research node using a meta-paradigmatic framework to untangle and clarify the different paradigmatic assumptions in the field of organizational communication research that has adopted the complexity science perspective. Our analysis revealed five research clusters that differ from each other in their understanding of what complexity is and in how they define communication. Based on our research, we present suggestions for finding common ground and reaching beyond simplistic dichotomies in complexity-based research.
\end{abstract}

Keywords: complexity theory, complex systems theory, organizational communication, organizational theory, meta-paradigmatic perspective, human resource development 


\section{Complexity and Organizational Communication: A Quest For Common Ground}

Since its introduction in the 1980s, complexity science has gradually grown to a

widespread movement within the social and organizational sciences. Some researchers in this field have promulgated the sharp contrast between complexity science and the reductionist Newtonian sciences, heralding a shift in the scientific world-view (Heylighen, Cilliers, \& Gershenson, 2007), whereas others have expressed their concerns about the loose metaphorical uses of complexity science by so-called complexity gurus (Maguire \& Mckelvey, 1999), as well as the methodological and philosophical problems with the theory (Daneke, 2005; Morrison, 2008). Despite such critiques, the complexity science has had a wide reach and influenced many organizational communication researchers.

In its various applications, the complexity science has challenged the ways of understanding organizational communication (Aula, 1996), change communication (Ströh, 2007), reputation (Murphy, 2010), and crisis communication and management (Gilpin \& Murphy, 2008; Liu \& Fraustino, 2014); helped to clarify the complex nature of conflict management (Aula \& Siira, 2007; Siira, 2013); drawn attention to the self-organizing aspects of group creativity (Poutanen \& Ståhle, 2014); provided a novel foundation for assessing organizational change (Salem, 2002); promoted the rethinking of the role of communication in the innovation process (Leeuwis \& Aarts, 2011) and knowledge creation (Stacey, 2001); and helped to establish a new model for studying organizational communication as a series of complex networks (Monge \& Contractor, 2003). Its potential value to human research development (HRD), a parallel field to organizational communication, has also been acknowledged (Iles \& Yolles, 2003). In addition, organizational communication researchers have contributed to the development of methodologies and methods of the complexity sciences and made them applicable to their own research context (Corman, Kuhn, McPhee, \& Dooley, 2002; Monge \& Contractor, 2003). 
The prevalence of studies inspired and informed by terminology, theories, methods, and ideas derived from the complexity science is vast. A common denominator in these studies is their use and application of various concepts of complexity science, such as selforganization, nonlinearity, emergence, complex networks, coevolution, fractals, bifurcations, autopoiesis, chaos, etc. However, as the range of different applications implies, the use of these concepts is manifold and unestablished. It is this richness that may have laid the foundation for criticism of the applications of complexity theory, especially in the humanities and social sciences, and other "soft sciences", where the methods and methodologies differ from those in the natural sciences. Besides the criticism directed at sloppy metaphorical applications of complexity theory (Byrne, 2005; Mckelvey, 1999; Pigliucci, 2000; Stewart, 2001), complexity theory itself has been criticized for a lack of theoretical and methodological coherence (Daneke, 2005; Morrison, 2008). On the other hand, there is no common understanding of the basic paradigmatic assumptions of complexity theory, even among the complexity scientists themselves — including the matter of defining complexity (Mitchell, 2009).

A large part of the critique is likely attributable to the relative youngness of the field and its position at the cross-section of the natural and social sciences, where the old discord between objectivist and subjectivist explanations remains. However, the field of complexity theory has also been less organized itself, leading to confusion that could have been avoided, had the scholars more clearly based their reasoning on certain paradigmatic underpinnings. Indeed, many complexity scholars themselves have seen as one of the most alarming shortages the fact that complexity-based studies lack reflexivity and epistemological sensitivity (Cilliers, 2000; Maguire, McKelvey, Mirabeau, \& Öztas, 2006; Richardson, 2011). A well demonstrated way to clarify such conceptual confusion and correct the absence of a paradigmatic context for the research is to examine the paradigmatic 
assumptions of the field, that is, ontology, epistemology, and methodology (Dewulf et al., 2009; Gioia \& Pitre, 1990). The aims of this article are to clarify the paradigmatic assumptions in the field of organizational communication research that has adopted the complexity science perspective, thereby contributing to the theoretical underpinnings of the complexity-based research in the organizational communication field, and to help establish a context for the discussion on communication phenomena from the complexity science perspective.

Accordingly, we have two objectives. First, we want to identify and untangle the different schools of complexity and explain them in relation to their paradigmatic assumptions. Such paradigmatic clarification will help future researchers identify the paradigmatic context of their own research and better assess the value of previous studies, thus contributing to better dialogue and reflexivity. This is an important task, as there is a large amount of complexity-based research, and it is most likely increasing. Second, by specifying the different paradigmatic assumptions, we want to investigate the complexitybased research conducted in the area of organizational communication and assess its relationship with these schools of complexity. In addition, we want to explore how the researchers conducting these studies understand the key concept of communication. Our aim here is to make the various perspectives visible, to inform the researchers about the ways of applying complexity theory within certain paradigmatic contexts.

To accomplish these tasks, we seek to answer the following research question: How can we categorize the complexity science based research conducted in the field of organizational communication, and what are the methodological, conceptual, and practical consequences of the adopted perspective?

We will continue this article by discussing briefly the background of complexity in the field of organizational research and then introducing the two main schools of complexity, 
namely, the objectivist and interpretivist schools (e.g., Maguire et al., 2006), and their paradigmatic assumptions. Then we will present the five clusters of complexity-based research that we identified in the literature on organizational communication: agent-based models, network of texts, meaning and interpretation, narratives and language, and living activity. For each cluster, we will provide examples of the research focus and analyze the paradigmatic assumptions and understandings of communication. Lastly, we will discuss the consequences of adopting a complexity science perspective for conducting research in the area of organizational communication.

\section{Perspectives on Complexity in the Field of Organizational Research}

The question of complexity has intrigued researchers since the emergence of sociological research in the mid-1800s. However, the enthusiasm for complexity did not bubble up in the social and cultural sciences until the 1990s, when applications of chaos theory emerged in these fields (Eve, Horsfall, \& Lee, 1997; Kiel \& Elliott, 1996). Today, the studies in the fields of organizational and social sciences and organizational communication are increasingly using complexity theory and complex adaptive systems theory (CAS) as research frameworks. Some advocates of complexity have suggested that the approach represents as radical a revolution as the Enlightenment period in society's challenging of the foundations of knowledge, science, and the economic, political, and social institutions built upon that knowledge (Maguire, 2011, p. 2).

Scholars have suggested that complexity science provides new theoretical perspectives, methodological approaches, and novel concepts derived mostly from the fields of mathematics and biology (Reilly \& Linds, 2010). In reality, there is no one "complexity theory"; rather, there is a set of different perspectives, theories, models, and ideas that researchers study under the rubric of complexity science. Thus, it must be stressed that complexity science is not a single, unified body of theory but an emerging approach (Walby, 
2007). Nor is it a methodology or toolbox but it provides "a conceptual framework, a way of thinking, and a way of seeing the world" (Mitleton-Kelly, 2003, p. 26; original emphasis removed). Therefore, this article will discuss the complexity-based theories, referring to the fact that not all studies explicitly refer to one complexity theory when using the ideas or concepts adopted from there.

Then, what is complexity science about? Complex systems are systems that comprise "a large number of entities that display a high level of nonlinear interactivity" (Richardson \& Cilliers, 2001, p. 8). At the heart of complexity is the idea that the research subject can be understood as a complex system, a web of many kinds of agents interacting in nonlinear ways and exhibiting collectively emergent patterns of behavior, that is, qualitatively different behavior that is non-reducible to the individual level (e.g. Cilliers, 1998). This property of complex systems that generates unpredictable macro-level structures is called emergence. The agents of complex systems both produce the macro-level structures and are simultaneously influenced by them (Maguire, 2011, p. 82). This view breaks away from the duality of agent and structure and sets the complexity perspective in contrast to strict methodological individualism or collectivism (see, e.g., Hodgson, 2007), akin to the agencystructure debate in sociology (Giddens, 1984; Sawyer, 2005).

It is important to understand that the words complex and complicated are not synonymous (Cilliers, 1998). Rather, complexity describes the deeply connected and interdependent nature of some systems. It is a state somewhere between order and disorder (Heylighen, 2008). Complexity scholars are interested in the change and evolution of a system over time, rather than its stable structures or states of equilibrium. Since complex systems are considered to be open systems, they evolve or coevolve with their environment and other systems. Hence, complex systems can generate change in their environment as well as adapt to changes in that environment. Furthermore, complex systems have the capacity to 
self-organize, meaning that they are able to respond to external perturbations by reorganizing internal structures through feedback loops (Gregson \& Guastello, 2011).

\section{Paradigmatic Approaches to Complexity in Organizational Research}

The paradigmatic concerns have inspired complexity scholars to produce a wealth of literature (see Maguire et al., 2006). There have been different attempts to organize internally the complexity-based research. One of the key divisions that organizational scholars applying complexity theory recognize is the one between the objectivist and interpretivist works. The objectivist approach tends toward positivism and draws heavily from the traditional natural scientific epistemology, whereas the interpretivist approach tends toward postmodernism or poststructuralism and adopts a meaning-based ontology and epistemology. Boisot and Child (1999), Maguire et al. (2006), and Morin (2007) discussed a similar division.

The two approaches propose seemingly different fundamental assumptions about the nature of complex systems (ontology), i.e., what they are; the knowledge about complex systems (epistemology), i.e., how we can know about them; and the ways to study those systems (methodology), i.e., how we can study them and what the most appropriate methods are. We will next go through these approaches by explaining how each of these schools addresses these paradigmatic questions.

The objectivist (or reductionist) approach to complexity is in line with the positivist scientific ideals, in that it aims at describing phenomena according to universal laws (Richardson \& Cilliers, 2001). Among the branches of complexity research that most likely fall into this category are the studies of self-organizing systems, deterministic chaos, and complex adaptive systems (Thietart \& Forgues, 2011, p. 56), which are essentially modelbased and mathematically oriented approaches. Ontologically speaking, complexity is an objective phenomenon caused by the structural intricacy, connectedness, and interdependency of the phenomenon under study (Maguire, 2011). Advocates of this 
approach use a positivistic method striving at filtering out the human subjectivity and formulating testable laws that they believe reflect the "true reality." In doing so, objectivists adopt an information-based stance "premised on the existence and accessibility of objective information about a given system" (Maguire et al., 2006, p. 174). That is, objectivist researchers tend to "elicit the most appropriate single representation" in order to restrict and simplify (i.e., reduce) the complexity (Boisot \& Child, 1999, p. 238; see also Maguire et al., 2006; Morin, 2007). The most frequently utilized methodological solution within this school of complexity is agent-based modeling (ABM), which researchers employ for simulating organizational phenomena. Specifically, ABM is used "to model aspects of complex systems by simulating self-organization, order creation and emergence of structures or cultures" (Maguire et al., p. 187). Lichtenstein and McKelvey (2004) identified more than 300 agentbased models relevant to organization studies. For example, researchers have used cellular automata to examine emergent economy, culture, and structure (Epstein \& Axtell, 1996), and the fitness landscape framework to study learning curves in technological evolution (Kauffman, 1995) and organizational adaptation (Levinthal, 1997). In addition, a significant amount of qualitative studies can be categorized as objectivist work. Such qualitative work typically aims to build theory that can be used to test hypotheses or that can be modeled computationally. For example, Brown and Eisenhardt (1997) use a multiple case study approach to explore how companies engage in continuous change in high-velocity industries. They challenge the punctuated equilibrium model of change and utilize the "edge of chaos" approach to demonstrate how companies benefit from partial order, a state between highly rigid and chaotic organization.

On the other hand, the interpretivist approach utilizes complexity theory mainly by employing its concepts that can be used as metaphors and heuristics of social life. Interpretivists usually maintain the incommensurability thesis, arguing that the social and 
natural sciences are sharply distinct from each other. Consequently, concepts such as chaos, self-organization, fractals, autopoiesis, etc. can only be used as illuminating conceptual tools that can help to present the phenomena of the social world in a new light. Thus, whereas objectivists start from the outset with the notion that human organizations really are complex systems, according to the interpretivist view, organizations should be considered as if they too are complex systems (e.g., Uden et al., 2001). Indeed, one of the known advocates of this approach, Stacey (1996), suggested that "[p]erhaps the science of complexity adds most value because it provides new analogies and metaphors for those in the research community" (p. 265). From this, it follows that complexity—like information in general—-has no objective existence but can be considered as a subjective, observer-oriented phenomenon reflecting the difficulty of representing and predicting the observed system (Maguire, 2011, p. 838). Along this line, organizations and their members should also be seen as interpretive, sense-making systems (Maguire et al., 2006, p. 175). Therefore, whereas objectivists aim at restricting complexity by formulating as objective explanations as possible within certain boundaries, interpretivists want to generalize or absorb complexity, i.e., try to provide as many divergent explanations of the phenomenon as possible, holding "multiple and sometimes conflicting representations" (Boisot \& Child, 1999, p. 238). As their methodological strategy, interpretivists have adopted different qualitative and narrative approaches. For example, the key advocate of the phenomenal complexity view, Letiche (2000), argued that understanding complex systems requires the acceptance of various valid truths, and stressed the need to pay attention to the experiencing subject. Moreover, Juarrero (1999) linked action theory to complexity science, and employed complexity theory as "a theory-constitutive metaphor" for rethinking causality. Finally, the interpretivists argue for the benefits of narrative methods in approaching complexity. According to Tsoukas and Hatch (2001), the narrative approach addresses important concepts—contextuality, reflexivity, expression of purposes and 
motives, and temporal sensitivity - that the traditional, logico-scientific approaches fail to address.

The presented dichotomy has its origin in the debates of organization science. For answering to the contemporary methodological debates, Burrell and Morgan (1979) identified different theoretical paradigms to be used in the research. The selection between these paradigms would then determine the philosophical stance and the selection of the appropriate method. However, to maintain a distinction between subjectivism and objectivism, has proved to be problematic in practice. Indeed, several more recent research perspectives allow more complicated relationship between the subject and the object than is often presented in the caricature-version of the dichotomy. Mong these perspectives are structuration theory, institutional theory, poststructuralism, and actor-network theory (see: Cunliffe, 2011, p. 652).

Cunliffe (2011) also reminds that more nuanced versions of objectivism exist nowadays than naive realism, such as critical realism, process and emergence theories, and discursive approaches. These approaches acknowledge the existence of the reality, but denies the possibility of non-perspective knowledge, as well as embrace contextual and relational nature of knowledge. Therefore, to claim that objectivism is only about "prediction" or a seek for universal laws, means committing the straw man fallacy. For example, the current version of scientific realism focuses on the exploration of generative mechanisms and complex causal processes (e.g. Hedström \& Ylikoski, 2011; Uhl-Bien, Marion, \& McKelvey, 2007; Byrne, 2011). Similarly, the notion of subjectivism has been much elaborated in its history, and also researchers there differ on their ontological stance, from seeing social reality as "objectified" and relatively stable to the notions of multiple interpretative realities, as Cunliffe reminds (2011).

Therefore, we want to emphasize that the role of this dichotomy here is not to fortify the old misleading oppositions. Rather, we see the dichotomy more as a continuum, including 
many kinds of research perspectives, which can be more objectivist or more subjectivist, or share characteristics of both tradition. The role that the dichotomy plays here can be described as a "guiding theory" that gives us a necessary perspective to the review (Torraco, 2005).

Table 1 outlines the different approaches to complexity in the organizational research, as suggested by our analytical framework. The horizontal dimension presents the different schools - the objectivist and the interpretivist — while the vertical dimension poses questions concerning the paradigmatic assumptions of the approaches and gives examples of possible research foci. The different schools reflect different conceptions of what a complex system is and how it should be studied. In addition, the research foci are different. The objectivist approach sees complexity as inherent in reality and considers complexity theory as the new "normal science" that reaches toward objectifying this complexity. The interpretivist approach, however, regards the idea of objectifying complexity with suspicion and sees complexity as an observer-originated phenomenon.

\section{[TAKE IN TABLE 1]}

Uncovering the ways to obtain knowledge about reality is a critical task for complexity scientists in all scenarios, since the very notion of complexity implies that simple and linear models are often insufficient and work only in specific circumstances. The objectivist school pins its hopes on the possibility of generating more accurate mathematical models and developing new method innovations, such as ABM and simulation strategies, that will eventually reveal the rules of the ever more complex reality. In contrast, interpretivists are not in the business of describing the reality but aim at providing rich interpretative accounts of the phenomenon at hand. For them, complexity theory serves as a source of inspiration and as a conceptual lens that reveals interesting and unseen parts of the phenomenon under study. 
Methods-wise, the objectivist school would favor mathematical and/or empirically testable models to gain knowledge about complex systems through empirical evidence, experimentation, and simulation methods. Interpretivists, on the other hand, would usually rely on language-based methods to elicit meanings and interpretations related to the systems under study, and would use metaphors and concepts as additional sources of inspiration or conceptual lenses for discovering new viewpoints regarding the studied phenomenon.

\section{Complexity-Based Research in the Field of Organizational Communication}

This section will use the framework outlined in the previous section to elicit the means of identifying the different clusters of complexity-based research within the organizational communication research. Table 2 identifies the clusters. We will subsequently describe each of these clusters and provide examples of their research foci and approaches to communication.

\section{[TAKE IN TABLE 2]}

\section{The Objectivist Work}

Within the objectivist work, there are two identifiable strands: agent-based models and network of texts.

Agent-based models and network analysis. Representing the first cluster, agentbased models are rooted in theories that typically acknowledge the dynamic nature of human interaction and organizing. Thus, they tend to integrate the interpretive aspects of communication within their models. Contractor (1994), for example, posited that a selforganizing systems perspective on organizational communication "bears the promise of building on insights gained from contemporary interpretive and critical research" (p. 57). He provided the example of "how structurational arguments to the study of the emergence of shared meaning in organizations can be articulated in a self-organizing systems framework" (Contractor, 1994, p. 53). He used three equations to articulate the underlying logic linking 
the variables of coordinated activity, shared interpretations, and environmental resources. What may appear to be a somewhat simple set of equations, Contractor (1994) argued, generate long-term dynamics that are beyond human understanding. The benefit of computer simulations in this regard is their ability to deduce precise hypotheses as well as theory building, not the model prediction or forecasting that are conventional in the physical sciences. Furthermore, Contractor and Grant (1996) employed the self-organizing systems perspective to re-conceptualize the emergence of shared interpretations and design a model simulating the process "by which a group of individuals who start out with some initial communication and semantic network configurations self-organize their subsequent levels of interactions (i.e. communication networks) and interpretations (i.e. semantic networks)" (p. 221).

Moreover, Monge and Contractor (2003) identified ABM as "a particularly useful framework to study the emergence of communication and knowledge networks" (p. 91), where the networks include both human agents (or aggregates of humans, such as groups and organizations) and nonhumans (e.g. computer software, mobile communication devices, avatars). They discussed the use of agent-based models to conceptualize these multi-agent knowledge networks as complex systems and the conditions under which such networks are likely to self-organize.

In their empirical study, Uddin, Hossain, Murshed, and Crawford (2010) studied changes in the communication network of a large organization during a crisis situation. They applied a temporal approach, i.e. they used dynamic network analysis instead of a more convenient approach of static "snap-shot" networks. They focused on a "complex email network" and showed how the dynamic approach can capture a more nuanced picture of the network behavior than the static approach. 
In the field of marketing, de Villiers (2015, in press) uses a complexity perspective to reframe consumer brand engagement theory $(\mathrm{CBE})$. The uses set theoretic models and asymmetric analytics in Boolean algebra (Ragin, 2008) for testing the principles of complexity in CBE. This study provides yet another novel analytical and methodological perspective for understanding and studying the dynamics of complex systems.

Network of texts. The second cluster includes the research aimed at capturing the dynamics of complex social collectives by examining organizational communication as a network of texts. Corman et al. (2002) touted the benefits of using centering resonance analysis (CRA), based on the theory of communicative coherence and centering, to study complex organizational communication systems. They pronounced CRA as "a flexible means of representing the content of large sets of messages, and assist in their analysis" (Corman et al., 2002, p. 159). According to them, existing research methods such as ethnographies, conversation analyses, questionnaires, and computational models "are inadequate for the task of testing claims about complex organizational communication systems" (Corman et al., 2002, p. 159). Thus, they argued that the benefit of CRA is its ability to operate simultaneously across different scales of aggregation and to utilize the actual words that people speak and write.

In their theoretical account, Dooley, Corman, McPhee, and Kuhn (2003) argued that modeling and understanding human systems necessitates capturing and closely analyzing the actual discursive processes between human agents, including the analysis of discourse that happens in different locales simultaneously. They proposed high-resolution, broadband discourse analysis (HBDA) as a novel approach to theorizing discourse, and CRA as an appropriate tool for collecting and analyzing texts. 


\section{The Interpretivist Work}

The interpretivist work comprises three identifiable clusters: meaning and interpretation, narratives and language, and living activity.

Meaning and interpretation. The third cluster is rooted in social constructionist premises (Berger \& Luckmann, 1966), and it views meaning and interpretation as essential characteristics of organizational communication. It also explicitly disengages itself from the traditional information transmission view of communication and connects with the cultural aspects of organizations. Aula (1996), for example, applied chaos theory concepts to model and understand organizational communication. From his perspective, such an approach calls for a meaning-oriented communication perspective based on the premises of constructivism. Therefore, Aula (1996) drew analogies to relevant chaos theory concepts (e.g., attractor, the butterfly effect, and bifurcation) and argued that an organization can be understood as a diverse set of cultures that are in recursive interaction with the organization's communications. Further, he conceptualized communication as two opposing forces that can be used as an effective tool to attain favorable outcomes for organizations by upholding tension and continuous struggle within the organizations (i.e., edge of chaos).

In a similar vein, Salem $(2002,2009)$ emphasized the meaning-making aspects of communication. He argued that communication is "an effort to make sense of an episode created by the process itself' (Salem, 2009, p. 97) and opposed the traditional approach that restricts communication to an exchange of messages between the sender and the receiver. Further, he stressed the relevance of paying attention to chaos and complexity theory concepts, such as a bifurcation point and an attractor, to achieve transformational, second order change in an organization's culture. Moreover, Salem, Barclay, and Hoffman (2003) utilized the complex adaptive systems approach to describe how an organization's culture approaches a bifurcation point during turbulent times. In their case study of a large 
government agency, they conducted interviews and analyzed texts to understand the evolution of organizational life and the communication underlying it.

In their empirical study, Sundstrom, Briones, and Janoske (2013) applied the concepts of complexity sciences in analyzing the crisis management of six non-profit organizations. They describe their approach as "postmodern" and apply content analysis techniques in analyzing the responses of the organizations (tweets, articles, documents, news releases). In conjunction with the complexity concepts lens, their analysis reveals how "the process of self-organization" facilitated calling publics to action and how coalition building utilizing various communication strategies becomes an important factor in the "dynamic environment."

McCarthy (2014) uses "chaos theory" as a conceptual lens for reframing the ideas of leadership, organization, and community in the context of movements of the African American systems in the $21^{\text {st }}$ century. This study illustrates how concepts derived from complexity sciences are suitable for reframing and rearticulating existing theories and interpretations of different historical situations.

Narratives and language. The fourth cluster departs from the meaning-centered work by explicitly stressing the importance of narratives, language, and discourse in constituting organizations. This cluster contains both macro and micro approaches. According to Luhman and Boje (2001), a narrative approach provides "a way to make concrete the concept of complexity science for organization studies" (p. 163). Drawing from chaos theory, they viewed organizational discourses as complex systems and identified one's storytelling power as an important attractor to allow for predictability in organizations. Furthermore, Tsoukas and Hatch (2001) conceptualized complexity science's value "as a guide for interpretation" (p. 981), rather than providing a theory with predictive validity. They advocated a narrative perspective on complexity, because "the system cannot speak for 
itself' (Tsoukas \& Hatch, 2001, p. 989); rather, one uses one's own language that is loaded with one's own goals and beliefs. Furthermore, Hawes (1999) used insights from cybernetic theory to advance a posthumanist theory of communication. He advocated dialogics as a means for theorizing narratives "that rethink and relocate human subjectivity as one-amongmany as well as some-over-others" (Hawes, 1999, p. 149). The narrative approach to complexity has gained wide attention within organizational studies. ${ }^{\text {ii }}$

Further, Leeuwis and Aarts (2011) viewed organizations as networks of actors, yet emphasized discourses, representations, and storylines for achieving organizational change. In particular, they discussed the concepts of self-organization and attractor landscapes, and proposed network-building, social learning, and conflict management as processes to which communication professionals should pay special attention in order to support innovation in organizations. Similar to Luhman and Boje (2001), they acknowledged the role of power in conceptualizing communication.

The micro approaches within this cluster refer to literature focusing on the languagein-action, small "d” analyses (Alvesson \& Kärreman, 2000). Isbell (2009), for example, illustrated the potential and applicability of various chaos theory concepts to the field of conversational analysis. Specifically, he recognized turn taking and topical shifting as "the locus of change" through which conversations become increasingly complex (Isbell, 2009, p. 24). Isbell (2009) argued that conversations are by nature chaotic systems, because they tend to be highly unpredictable, thus dealing with nonlinear dynamics, and they involve various interplaying variables. According to Isbell (2009), chaos theory provides "at the very least... new verbiage to talk about and fresh theoretical frameworks" (p. 23) for analyzing conversations. Furthermore, Bloom (2001) characterized an argument as a chaotic system. He examined transcripts of classroom discussions and concluded with a representation of the 
argument's emergent structure based on elements from chaos theory (i.e., the argument as a self-maintaining dissipative structure).

Living activity. The final cluster differs from the previous two interpretivist clusters by arguing for the importance of focusing on the present, living activity to understand the dynamic processes of human interaction. Shotter and Tsoukas (2011) criticized the analytical-representational (intellectualist) orientation toward narrative and language-based theory building that aims to justify and explain social phenomena retrospectively and from an outside position. Instead, they advocated a relational-responsive perspective that aims at "working from within a relevant phenomenon" (Shotter \& Tsoukas, 2011, p. 337; emphasis in the original). Their "ecological approach" highlights the emergent features of human activities that arise from "relationality, contextual specificity, and reflexivity" (Shotter \& Tsoukas, 2011, p. 344). They posited that the benefit of a complexity science approach to the study of social interaction nests in the so-called relational imagery that complexity evokes, because it enables one to better deal with relational uniqueness and emergent change.

Similar to Shotter and Tsoukas (2011), Hoffman (2008) advocated a perspective that focuses on the living present that "never takes its eyes off interaction activity" (p. 433; emphasis in the original). Drawing from the work of Stacey, Griffin, and Shaw (Shaw, 2004; Stacey, Griffin, \& Shaw, 2000; Stacey, 2001), Hoffman (2008) distinguished the transformative strand of complexity science as "a profound break" from the deterministic views of causality that dominate systems science. She viewed communicative interaction as embodied activity, which expands the conceptualization of sense making beyond one's abstract thinking capacity. Developments in neuroscience (Damasio, 2003) have pointed toward embodied aspects of human sense making, which Hoffman (2008) argued is integral for communication scholars as well. 
In her action research focusing on organizational change processes, Kristiansen (2013) likewise uses Stacey’s (2001) approach on “complex responsive processes.” She discusses how Stacey's approach presents a theoretical understanding of the relationship between communication and organization, in which there is no separation between them. According to Kristiansen, the complex responsive processes approach suggests that "human bodies are situated in complex situations, where they participate in processes of interaction by gesturing and responding" (p. 101). She defines "complex" as situations in which "voices and interests meet in unforeseen ways"(p. 101).

In sum, the objectivist literature views organizations as networks of communicating agents or text and utilizes computational modeling and sophisticated mathematical analyses to capture the complexities of organizing. This approach stresses the importance of adding precision and rigor to the study of organizational communication as a dynamic process (Contractor, 1994) and the need for techniques and methodologies that are capable of handling large quantities of communication (Corman et al., 2002). The studies categorized especially under the first cluster (Agent-based models and network analysis) represent probably the most ambitious and far-reaching quantitative developments in the area of organizational communication research. This work has its legacy in the foundational studies of Santa Fe -institute and the development of CAS methodologies. In this research tradition of complex systems, a seek for finding a common theoretical framework and characteristics of complex systems, as well as the embrace of computational methods, has been among the importantn goals of the institution and the surrounding research community (see e.g. Waldrop, 1992; Dodder \& Dare, 2000).

The interpretivist work, on the other hand, draws mainly from the constructivist and interpretive foundations and favors subjective interpretations and the relationality of meaning and action, and focuses on symbolic means of communication, such as text or narratives. The 
studies categorized under the fifth cluster (Living activity) come actually very close to what Cunliffe (2011) calls "intersubjective problematic" (p. 657) and considers as an important addition to the objectives-subjectivism dichotomy. Intersubjectivity stands for relational perspective on human interaction and emphasizes responsive ways of being present together, in a form of co-presence and co-existence. Cunliffe argues that intersubjectivity differs from subjectivity in its emphasis on we-ness and active relationships (p. 658), and therefore it also offers one possible jumping off point for researchers who strive for looking for novel approaches to subjective perspectives.

Three noteworthy aspects contextualize our findings. First, the line between studies on organizations in general and the research of organizational communication scholars seems somewhat blurry in relation to the complexity-based research. On the one hand, such constructs as communication, information, and knowledge are important concepts in organizational scholars' works across different research communities. On the other hand, organizational communication and general organizational studies researchers alike have participated in the philosophical debates on the role of complexity (Contractor, 1999; Luhman \& Boje, 2001; Tsoukas \& Hatch, 2001).

Second, complexity theory and communication theories share much of the same roots in the early formulations of systems theories and information theory. In particular, structuralfunctionalism, cybernetics, and general systems theory have been important to the study of organizational communication (Monge \& Contractor, 2003). In light of these notions, it is not surprising that complexity theory has gained increasing attention from organizational communication scholars.

Third, the organizational communication scholars have long identified and debated similar paradigmatic differences when defining the research field (Corman \& Poole, 2000; Krone, Jablin, \& Putnam, 1987). Perhaps the clearest distinction has been made between the 
system-oriented and interpretation-oriented research streams. This distinction can be presented in the form of a question concerning what the role of communication is in relation to organizations. That is, on the one hand, communication has been seen as the central means by which organizational members' activities are coordinated to achieve organizational goals, while, on the other hand, communication has also been considered the core process of organizing (Jones, Watson, Gardner, \& Gallois, 2004). These perspectives are often called the transmission view and the interpretative view, respectively (Aula \& Siira, 2007). The former has its roots in traditional information theories, such in the mathematical models of information (Shannon \& Weaver, 1949), and the latter in interpretative theories (Carey, 1975; Weick, 1979, 1995). Recently, the latter perspective emphasizing "communication as organizing"-rather than "communication in organizations"- - has gained increasing attention from the scholars who have gathered under the rubric of the "communicative constitution of organization” or the CCO (Mcphee \& Zaug, 2000; Taylor \& Van Every, 2000).

In the complexity-based communication research, there have been many different approaches with regard to the phenomenon of communication. In general, the objectivist complexity-based studies have approached communication as networks of actors participating in information exchange and knowledge creation. According to this approach, both agent-wise and semantic relations uncover how agents' actions, relations, and discourses form and evolve in the processes of organizing.

The interpretivist complexity-based studies have adopted a different stance on the applicability of complexity theory and have used language and meaning-making processes as their starting points; it is the ongoing negotiation of meanings that can be understood through complexity terms. On the other hand, some researchers have emphasized the narrative, rather than representative, nature of human communication and organizing, and have seen stories and conversational patterns as complex and chaotic processes themselves. Yet others have 
emphasized the interactions of the communicators and have regarded organizing as a collective and relational sense-making process embedded and embodied in the actions and interactions of the agents.

\section{Discussion}

This section first discusses on many of the critical remarks made about studies working from perspective of complexity sciences. The most important critics have been summarized and reflected against the organizational communication literature. Secondly, this section discusses the implications and possibilities that complexity perspective can provide for HRD researchers and practitioners. Thirdly, the discussion is closed by authors' presentation of a future research agenda of complexity-based studies in organizational communication, HRD, and other related fields.

\section{Critical reflections on complexity-based research}

There have been numerous critical remarks about complexity theory and its applications in, and applicability to, the organizational communication research. Three areas of analysis seem particularly relevant to the existing complexity-based organizational communication literature: an overt use of metaphors, a lack of reflexivity, and a lack of empirical evidence. They are important to discuss here because complexity sciences applications have also faced harsh criticism, and one of the purposes of this article is to contextualize this criticism in relation to paradigmatic assumptions.

First, the literature review indicates that metaphors and analogies are the main tools for employing the complexity concepts in the organizational communication literature. The extensive use of metaphors and analogies is characteristic of the complexity literature in the social and organizational sciences in general. We do not take a negative stance regarding the use of metaphors and analogies (certainly, they play an important role in the creative formulation of new models and perspectives; see e.g. Uden et al., 2001). Indeed, in the realm 
of organizational communication we can find processes, which could be approached from the complexity sciences perspective as analogies. For example, such communication events as the construction of communication relations, spreading of rumours, or changes in public opinion could be though of as periodic systems, in which the output of the last event is the input of the following. Following the analogy of non-linearity here, small and seemingly insignificant changes on the communication micro level can grow in strength, which effects the macro level organization (Aula, 1999).

What we regard as more alarming is the lack of reflexivity in the utilization of the complexity concepts in the organizational communication research. That is, some scholars employ complexity concepts as lenses and tools without acknowledging the limitations of the approach. For example, Isbell (2009) pulled concepts from chaos theory and highlighted their heuristic potential and applicability in conversation analysis, yet did not offer a word of caution about the limitations of this approach. Furthermore, Salem et al. (2003) integrated the concept of a bifurcation point as a metaphorical lens in their analysis of organizational change, making the transfer from natural sciences to the social domain nonchalantly. What was missing was reflection on the concept and the limits of its applicability to the studied phenomenon of organizational change.

Thus, it is no wonder that there has been criticism of the practice of casually importing the models, theories, and concepts from the physical and life sciences to the study of social phenomena (Burnes, 2005). Some scholars (e.g. Rosenhead, 1998) see this as problematic partly because organizational scholars have been employing the concepts of complexity despite the questioning of their validity in the field of natural sciences, leading to a superficial reference to "scientific authority" without real scientific evidence. On the other hand, other scholars have pointed out that researchers applying complexity concepts have not paid enough attention to the hard scientific origin of the concepts, and have used them in 
rather non-specific and sometimes even confusing ways (Maguire \& Mckelvey, 1999; Rosenhead, 1998).

Second, there is also an apparent lack of empirical evidence in the complexity literature on organizational communication. Much of the literature is conceptual or theoretical in nature, introducing the complexity approach to a specific area of study (e.g. Leeuwis \& Aarts, 2011), providing alternative views or methods to the analysis (e.g. Corman et al., 2002), or reflecting the use of complexity science in the communication research in general (e.g. Tsoukas \& Hatch, 2001). The lack of empirical evidence is characteristic of both the objectivist and interpretivist work. Contractor and Grant (1996), for example, proposed mathematical modeling to deduce hypotheses from simulation data, which does not include empirical data itself but requires follow-up studies to validate the hypotheses. Similarly, Aula (1996) drew from the mathematical basis of chaos theory and advanced a model of communication without empirical data.

Overall, the lack of empirical data is not entirely surprising, given that complexity approaches are rather new to the social sciences. On the other hand, as Corman et al. (2002) noted, communication researchers are "ill equipped" (p. 158) to study complex organizational communication phenomena using the existing research methods. Thus, many speculative writings and considerable theoretical modeling are based on computer simulations, illustrative examples, anecdotal empirical cases, and analogies and metaphors; however, these do not amount to empirical evidence (Contractor, 1999, p. 156; Corman et al., 2002; Scott, 2002).

We posit, however, that the lack of empirical evidence is not a pivotal hindrance to the advancement of the research on complexity-based organizational communication. Many methods are needed, including the non-empirical approaches from the metaphoric stance. Complexity scholars have admitted to the value of many kinds of methods and tools, and, in 
essence, there is no need to refrain from using certain concepts as tools for theorizing, providing they illuminate the studied phenomenon in some important ways. The value of theorizing is, however, further valued in the debates of organizational communication and empirical evidence, not in the authenticity of the use of an original idea (cf. Cohen, 1994; Stewart, 2001). iii

\section{Implications of complexity on the practice and theory of HRD}

We concur with previous notions of complexity science's potential value to HRD (i.e. Iles \& Yolles, 2003) and believe that it could contribute significantly to the practice and research of HRD, which has firm roots in system theory (e.g. Gradous, 1989; Swanson, 2001; Jacobs, 2014).

On one hand, complexity science offers a fresh framework to rethink the basic assumptions and tenets of traditional HRD thinking and provides a rich source of metaphors to guide the design of organizational processes and actions (Maguire, Allen \& Kelvey, 2011). On the other hand, it offers a variety of conceptual and methodological tools to "tackle the issues of emergence, self-organization, evolution and transformation" (Maguire, et al., p. 10), which seem relevant also in the HRD's quest for improving organizational and individual performance. In fact, HRD and complexity seem compatible in many ways; they are both highly multidisciplinary in nature, aim to understand organizational functioning, and harness the potential of organizations. The two fields also share various research areas such as organizational change (Eyoang, 2011), organizational learning (Mitleton-Kelly \& Ramalingam, 2011), and innovation (Andriani, 2011).

Of most interest to us is the literature in the intersection of complexity theory and organizational communication, which provides a few interesting insights and potential directions for HRD as well. Leeuwis and Aarts (2011) for example rethink the role of change agents in innovation development and design, an area essential to HRD professionals as well 
(e.g. Waight, 2005; Loewenberger, 2013). They utilize the concept of self-organization and define innovation as "a collective process that involves the contextual re-ordering of relations in multiple social networks (p. 21). From this perspective, the aim of organizational interventions shifts from striving for predefined change to facilitating "space for change". In practice, this could be done by network building to re-configure relationships within and between networks, form new networks, and terminate existing networks, supporting social learning to develop a favorable fit between innovations and their environment, and conflict management to overcome resistance.

Siira (2012) in turn utilizes the complexity approach to reconceptualize managerial influence in conflicts, which has also been an area of interest to HRD (e.g. Kochery, 1993; Trudel \& Reio, 2011). According to Siira, the view of organizations as complex and dynamical systems challenges the dominant, resolution-oriented view of conflict management, where the focus of managerial influence is on direct and sporadic interventions. The complexity perspective highlights the value of polyphony and diversity in organizations, which requires skills to continuously balance the opposing tendencies and preserve diversity. Managers should thus be encouraged and trained to help conflict parties voice their views, withdraw from pushing their own views, and pay close attention to language maintenance i.e. the content and patterns of conflict conversation (Ford, 1999). Regardless of the paradigmatic orientation they represent, they stress the principle of unpredictability in complex human organizations, which rejects calculated interventions in order to get predefined outcomes. The complexity approach does not however exclude the role of external influence or change agents; rather, it places emphasis on low-level, bottom-up processes that produce emergent, potentially transformative outcomes in specific contexts as illustrated by Leeuwis and Aarts and Siira. 
In sum, communication scholars of complexity pay close attention to the micro-level interactions and processes to achieve long-term effectiveness and improved performance in organizations. The same focus has indeed also emerged lately within the complexity scholars interested in studying "human interaction dynamics" in an attempt to better link individual actions and organization processes and outcomes (Hazy \& Backström, 2013; Hazy Ashley, 2011). The perspective adopted by these researchers resonates strongly with those in the areas of organizational communication and HRD and represents a promising research avenue for them.

\section{Suggestions for a future research agenda for complexity-based research}

Despite the critical remarks made about the foundations and applications of complexity sciences in organizational communication literature, we suggest that it provides an important theoretical opening for accounting for the complexities of organizational communication phenomena. To this end, we present three suggestions for how complexitybased research and research programs can be better equipped to lay strong scientific foundations. Our suggestions, following the lines presented by Salem (2009), Poole and Lynch (2000), and Poole (2014), among others, focus on ways of finding common ground and reaching beyond the simple dichotomies of "qualitative" and "quantitative." Indeed, we agree with notion made by Hazy et al. (2013) according to which human interaction and organizations could be studied from the complexity perspective in a complement way "rather than replace existing approaches that tend to place their emphasis on inter-subjectivity and meaning-making rather than on the objective measurement of information as a physically measurable quantity" (p. 91). In particular, we adopt three different perspectives on finding this common ground.

The first suggestion relates to ways of finding common ground through the methodological design applied in complexity-based studies. For example, Salem (2009) 
discusses how a "mixed design" approach could prove useful in this respect. Mixed design refers to purposefully combining qualitative and quantitative methods in one research design. Salem points out that demonstrating complexity in data may involve a large amount of data points, collected over a long period, which is not common in many quantitative research settings (p. 214-5). However, a qualitative approach would add richness and depth, and quantitative methods would extend the temporal breadth of a study, explains Salem (p. 215). In practice, it is possible to combine quantitative and qualitative approaches in many ways (Mingers, 2001). One possible mix is the interplay of "formal" empirical system models and “informal” descriptive and conceptual models, as Poole (2014), for example, has suggested. Formal models can be used as sources of information for informal analysis, which in turn can suggest new ideas to enrich formal analysis (Poole, 2014, p. 60). In communication studies more effort is required in order to brake down the barriers between qualitative and quantitative approaches. Otherwise we will loose the change to utilize the possibilities offered by mixed methods complexity approach. Another possible mix is to use methods in sequence. Communication researchers can, for example, employ simulation methods as part of the design. Salem (2009, p. 216) uses the example of a study by Stephens et al. (2007) in which qualitative data was gathered on communication and decision processes, data that was then used as an input for constructing a simulation to demonstrate quantitatively the generalized abilities of the observed patterns.

The second suggestion relates to ways of finding common ground through the conceptual development of complexity-based communication studies. For example, Poole and Lynch (2000) discussed different strategies and suggested using a theory that cuts across perspectives. This strategy suggests a "transcendent theory" that makes a move on a “different metalevel of analysis" and goes "beyond existing perspectives" (p. 221). According to them, structuration theory is an example of such a theory in its denial of 
subjective and objective sides of inquiry and the adoption of a dualistic approach, whereby structure and action/meaning together produce reality. In essence, no one paradigm can fully capture the reality, but rather provides a perspective on it - a position called critical pluralism (Mingers, 2001). In this sense, complexity sciences themselves provide a meta-theoretical lens that can be used and developed to understand both the structure (system-level/collective phenomena) and action (rules guiding agents' behaviors) and the interplay between them (upward and downward causation/emergence; see Maguire, 2011). In organizational communication context adopting this view means that we could conceptualize organization as complex system where the organization's macro-level structures arise out from local arenas of communicative interactions (Aula, 1999). In addition, macro-level events also affect the very activity from which it arises. Thus seemingly erratic local behaviour may be quite ordered from a macro-structure perspective. Aula (1999) continues that in practise this means that we should approach an organization as being created both from the bottom up and from top down in a recursive manner. Descriptions from either side alone are inadequate.

The third suggestion relates to ways of finding common ground through the development of novel research practices in complexity-based studies. A possible strategy to overcome the chasm of different paradigms is to accept the differences in the perspectives and foster a dialogue between them (Poole \& Lynch, 2000). This "complementarity" approach does not aim at either integration or finding overlapping points of reference from the different discourses. Rather it focuses on stimulating productive scholarship and dialogues through focusing on common problems (p. 221). The complexity approach seems to necessitate various research skills, ranging from general theoretical and philosophical understanding to subject-related theoretical understanding and methodological knowledge and skills, such as computing and mathematics, reaching well beyond the expertise of traditional social scientists and organization researchers. Thus, interdisciplinary research 
practices, such as multi-disciplinary research groups, should be fostered in communication studies.

\section{Conclusion}

In this paper, we discussed the relationship between complexity theory and the organizational communication research. As such, we concentrated on the complexity-based research conducted in the field of organizational communication by using the frames of different paradigmatic assumptions. Further, we identified five clusters — agent-based models, network of texts, meaning and interpretation, narratives and language, and living activitywithin the objectivist and interpretivist paradigms in the complexity and organizational communication research. The boundaries between the different clusters are not definitive; the clusters interact in many ways and share some similarities, such as the focus on text and speech in both paradigms and the focus on organizations as networks. However, they also differ from each other in their research objectives, such as analyzing the meanings of large quantities of textual data or focusing on micro-level conversational dynamics or discursive levels of language.

Two major views of communication - the transmission and interpretative views - see communication either as the transmission of messages or a meaning-based process of coordinating and organizing actions. These views need not be exclusive; rather, they can be critically and reflectively used in various research contexts and for various purposes. The complexity-based research uses various definitions of communication, from information transmission to text, discourses, and behavioral patterns and relational activities.

The future complexity-based research would benefit from considering and clarifying its paradigmatic preferences, as well as adopting a reflexive stance on its research objective and that knowledge that the research produces, whether objective or interpretative in nature. 


\section{References}

Alvesson, M., \& Kärreman, D. (2000). Varieties of discourse: On the study of organizations through discourse analysis. Human Relations, 53(9), 1125-1149.

http://dx.doi.org/10.1177/0018726700539002

Aula, P. (1996). Chaos and the double function of communication. In W. Sulis \& A. Combs (Eds.), Nonlinear dynamics in human behavior (pp. 191-206). Singapore: World Scientific.

Aula, P., \& Siira, K. (2007). Towards social complexity view on conflict, communication, and leadership. In J. K. Hazy, Jeffrey A. Goldstein, \& B. B. Lichtenstein (Eds.), Complex systems leadership theory (pp. 367-384). Boston, MA: ISCE Publishing.

Berger, P. L., \& Luckmann, T. (1966). The social construction of reality. New York: Anchor.

Bloom, J. W. (2001). Discourse, cognition, and chaotic systems: An examination of students' argument about density. Journal of the Learning Sciences, 10(4), 447-492.

Boisot, M., \& Child, J. (1999). Organizations as adaptive systems in complex environments: The case of China. Organization Science, 10(3), 237-252. http://dx.doi.org/10.1287/orsc.10.3.237

Brown, S. L., \& Eisenhardt, K. M. (1997). The art of continuous change: Linking complexity theory and time-paced evolution in relentlessly shifting organizations. Administrative Science Quarterly, 42(1), 1-34. http://dx.doi.org/10.2307/2393807

Byrne, D. (2005). Complexity, configurations and cases. Theory, Culture \& Society, 22(5), 95-111. http://dx.doi.org/10.1177/0263276405057194

Carey, J. W. (1975). A cultural approach to communication. Communication, 2(1), 1-22. 
Cilliers, P. (1998). Complexity and postmodernism: Understanding complex systems. London: Routledge.

Cilliers, P. (2000). Knowledge, complexity, and understanding. Emergence, 2(4), 7-13. http://dx.doi.org/10.1207/S15327000EM0204_03

Cohen, I. B. (1994). Interactions: Some contacts between the natural sciences and the social sciences. Cambridge, Massachusettes: MIT Press.

Contractor, N. S. (1994). Self-organizing systems perspective in the study of organizational communication. In B. Kovacic (Ed.), New approaches to organizational communication (pp. 39-65). Albany, NY: Suny Press.

Contractor, N. S. (1999). Self-Organizing systems research in the social sciences: Reconciling the metaphors and the models. Management Communication Quarterly, 13(1), 154-166. http://dx.doi.org/10.1177/0893318999131009

Contractor, N. S., \& Grant, S. (1996). The emergence of shared interpretations in organizations: A self-organizing systems perspective. In J. Watt \& A. VanLear (Eds.), Cycles and dynamic processes in communication processes (pp. 216-230). Newbury Park, CA: Sage.

Corman, S. R., Kuhn, T., McPhee, R., \& Dooley, K. (2002). Studying complex discursive systems: Centering resonance analysis of communication. Human Communication Research, 28(2), 157-206. http://dx.doi.org/10.1093/hcr/28.2.157

Corman, S. R., \& Poole, M. S. (Eds.). (2000). Perspectives on organizational communication: Finding common ground. New York: The Guilford Press.

Damasio, A. (2003). Looking for Spinoza: Joy, sorrow, and the feeling brain. Orlando, FL: Harcourt. 
Daneke, G. A. (2005). The reluctant resurrection: New complexity methods and old systems theories. International Journal of Public Administration, 28(1-2), 89-106. http://dx.doi.org/10.1081/PAD-200044569

de Villiers, R. (2015, in press) Consumer brand enmeshment: Typography and complexity modelling of consumer brand engagement and brand loyalty enactments. Journal of Business Research (2015), http://dx.doi.org/10.1016/j.jbusres.2015.01.005

Dewulf, A., Gray, B., Putnam, L., Lewicki, R., Aarts, N., Bouwen, R., \& van Woerkum, C. (2009). Disentangling approaches to framing in conflict and negotiation research: A meta-paradigmatic perspective. Human Relations, 62(2), 155-193. http://dx.doi.org/10.1177/0018726708100356

Dooley, K., Corman, S. R., McPhee, R., \& Kuhn, T. (2003). Modeling high-resolution broadband discourse in complex adaptive systems. Nonlinear Dynamics, Psychology, \& Life Sciences, 7(1), 61-85.

Epstein, J. M., \& Axtell, R. (1996). Growing artificial societies: Social science from the bottom up. Cambridge, MA: MIT Press.

Eve, R. A., Horsfall, S., \& Lee, M. E. (1997). Chaos, complexity, and sociology: Myths, models, and theories. Thousand Oaks, CA: Sage.

Giddens, A. (1984). The Constitution of society: Outline of the theory of structuration. Cambridge: Polity Press.

Gilpin, D. R., \& Murphy, P. J. (2008). Crisis management in a complex world. New York: Oxford University Press.

Gioia, D. A., \& Pitre, E. (1990). Multiparadigm perspectives on theory building. The Academy of Management Review, 15(4), 584-602. http://dx.doi.org/10.2307/258683 
Gregson, R. A. M., \& Guastello, S. J. (2011). Introduction to nonlinear dynamical systems analysis. In S. J. Guastello \& R. A. M. Gregson (Eds.), Nonlinear dynamical systems analysis for the behavioral sciences using real data (pp. 1-16). Boca Raton: CRC Press.

Hawes, L. C. (1999). Dialogics, posthumanist theory, and self-organizing systems. Management Communication Quarterly, 13(1), 146-153. http://dx.doi.org/10.1177/0893318999131008

Hempel, C. G. (1977). Formulation and formalization of scientific theories. In F. Suppe (Ed.), The structure of scientific theories (2nd ed., pp. 244-265). Urbana: University of Illinois Press.

Heylighen, F. (2008). Complexity and self-organization. In M. J. Bates, M. Niles, \& M. Taylor (Eds.), Encyclopedia of Library and Information Sciences (3rd ed., pp. 1-20). London: Taylor \& Francis.

Heylighen, F., Cilliers, P., \& Gershenson, C. (2007). Philosophy and complexity. In J. Bogg \& R. Geyer (Eds.), Complexity, science and society (pp. 117-134). Oxford: Radcliffe Publishing.

Hodgson, G. M. (2007). Institutions and individuals: Interaction and evolution. Organization Studies, 28(1), 95-116. http://dx.doi.org/10.1177/0170840607067832

Hoffman, R. (2008). Exploring the link between uncertainty and organizing processes: Complexity science insights for communication scholars. Communication Theory, 18(3), 426-447. http://dx.doi.org/10.1111/j.1468-2885.2008.00329.x

Isbell, M. J. (2009, Nov). Conversational chaos: Order and complexity in everyday conversations. Paper presented at the annual meeting of the NCA 95th Annual Convention, Chicago Hilton \& Towers, Chicago, IL. 
Jones, E., Watson, B., Gardner, J., \& Gallois, C. (2004). Organizational communication: Challenges for the new century. Journal of Communication, 54(4), 722-750. http://dx.doi.org/10.1093/joc/54.4.722

Juarrero, A. (1999). Dynamics in action: Intentional behavior as a complex system. Emergence, 2(2), 24-57. http://dx.doi.org/10.1207/S15327000EM0202_03

Kauffman, S. A. (1995). At home in the universe: The search for the laws of self-organization and complexity. New York: Oxford University Press.

Kiel, L. D., \& Elliott, E. (1996). Chaos theory in the social sciences: Foundations and applications. Ann Arbor, MI: The University of Michigan Press.

Kristiansen, M. (2013). Dynamics between organisational change processes and facilitating dissensus in context inquiring dialogues. International Journal of Action Research, 9(1), 95-123.

Krone, K. J., Jablin, F. M., \& Putnam, L. L. (1987). Communication theory and organizational communication: Multiple perspectives. In F. M. Jablin, L. L. Putnam, K. H. Roberts, \& L. W. Porter (Eds.), Handbook of organizational communication: An interdisciplinary perspective (pp. 18-40). Newbury Park: Sage Publications.

Leeuwis, C., \& Aarts, N. (2011). Rethinking communication in innovation processes: Creating space for change in complex systems. The Journal of Agricultural Education and Extension, 17(1), 21-36. http://dx.doi.org/10.1080/1389224X.2011.536344

Letiche, H. (2000). Phenomenal complexity theory as informed by Bergson. Organizational Change Management, 13(6), 545-557. http://dx.doi.org/10.1108/09534810010378579

Levinthal, D. A. (1997). Adaptation on rugged landscapes. Management Science, 43(7), 934950. http://dx.doi.org/10.1287/mnsc.43.7.934 
Lichtenstein, B. M., \& McKelvey, B. (2004, August). Complexity science and computational models of emergent order: What's there? What's missing? Paper presented at the Academy of Management Annual Meeting, New Orleans, LA.

Liu, B. F., \& Fraustino, J. D. (2014) Beyond image repair: Suggestions for crisis communication theory development. Public Relations Review, 40(3), 543-546. http://dx.doi.org/10.1016/j.pubrev.2014.04.004

Luhman, J. T., \& Boje, D. M. (2001). What is complexity science? A possible answer from narrative research. Emergence, 3(1), 158-168. http://dx.doi.org/10.1207/S15327000EM0301_10

Maguire, S. (2011). Constructing and appreciating complexity. In P. Allen, S. Maguire, \& B. Mckelvey (Eds.), The Sage handbook of complexity and management (pp. 79-92). Los Angeles: Sage.

Maguire, S., \& Mckelvey, B. (1999). Complexity and management: moving from fad to firm foundations. Emergence, 1(2), 19-61. http://dx.doi.org/10.1207/s15327000em0102_3

Maguire, S., McKelvey, B., Mirabeau, L., \& Öztas, N. (2006). Complexity science and organization studies. In S. R. Clegg, C. Hardy, T. Lawrence, \& W. R. Nord (Eds.), The Sage handbook of organization studies (pp. 165-214). London: Sage.

McCarthy, L. D. (2014) Chaos Theory: Towards an alternative perspective of African American leadership, organization, and community systems. Journal of Alternative Perspectives in the Social Sciences, 6(2), 122-155.

Mckelvey, B. (1999). Complexity theory in organization science: Seizing the promise or becoming a fad? Bottom-up organization science. Emergence, 1(1), 5-32. 
Mcphee, R. D., \& Zaug, P. (2000). The communicative constitution of organizations: A framework for explanation. Electronic Journal of Communication/La Revue Electronique de Communication, 10(1-2), 1-16.

Mingers, J. (2001). Combining IS research methods: Towards a pluralist methodology. Information System Research, 12(3), 240-59. http://dx.doi.org/10.1287/isre.12.3.240.9709

Mitchell, M. (2009). Complexity: A guided tour. New York: Oxford University Press.

Mitleton-Kelly, E. (2003). Ten principles of complexity \& enabling infrastructures. In E. Mitleton-Kelly (Ed.), Complex systems and evolutionary perspectives on organisations: The application of complexity theory to organisations (pp. 21-50). Kidlington, Oxford: Elsevier Science.

Monge, P. S., \& Contractor, N. S. (2003). Theories of communication networks. Oxford: Oxford University Press.

Morin, E. (2007). Restricted complexity, general complexity. In C. Gershenson, D. Aerts, \& B. Edmonds (Eds.), Worldviews, science and us: Philosophy and complexity (pp. 5-29). Singapore: World Scientific.

Morrison, K. (2008). Educational philosophy and the challenge of complexity theory. Educational Philosophy and Theory, 40(1), 19-34. http://dx.doi.org/10.1002/9781444307351.ch2

Murphy, P. (2010). The intractability of reputation: Media coverage as a complex system in the case of Martha Stewart. Journal of Public Relations Research, 22(2), 209-237. http://dx.doi.org/10.1080/10627261003601648

Pigliucci, M. (2000). Chaos and complexity: Should we be skeptical? Skeptic, 8(3), 62-70. 
Poole, M. S. (2014). Systems Theory. In L. L. Putnam \& D. K. Mumby (Eds.), The Sage handbook of organizational communication (pp. 49-74). Thousand Oaks, CA: Sage.

Poole, M. S., \& Lynch, O. H. (2000). Reflections on finding common ground. In S. R. Corman \& M. S. Poole (Eds.), Perspectives on organizational communication: Finding common ground (pp. 211-24). New York: The Guilford Press.

Poutanen, P. K., \& Ståhle, P. (2014). Creativity in short-term self-directed groups: An analysis using a complexity-based framework. International Journal of Complexity in Leadership and Management, 2(4), 259-277. http://dx.doi.org/10.1504/IJCLM.2014.064455

Ragin, C. C. (2008). Redesigning social inquiry: Fuzzy sets and beyond. Chicago, IL: University of Chicago Press.

Reilly, R., \& Linds, W. (2010). Complexity. In A. J. Mills, G. Durepos, \& E. Wiebe (Eds.), Encyclopedia of case study research (pp. 180-183). Thousand Oaks, CA: Sage.

Richardson, K. A. (2011). Complexity and management: A pluralistic view. In S. Maguire, P. Allen, \& B. McKelvey (Eds.), The Sage handbook of complexity and management (pp. 366-382). Thousand Oaks: Sage.

Richardson, K. A., \& Cilliers, P. (2001). Special editor's introduction: What is complexity science? A view from different directions. Emergence, 3(1), 5-23.

Rosenhead, J. (1998). Complexity theory and management practice. Working paper series, LSEOR 98.25, London School of Economics, London.

Salem, P. (2002). Assessment, change, and complexity. Management Communication Quarterly, 15(3), 442-450. http://dx.doi.org/10.1177/0893318902153006

Salem, P. (2009). The complexity of human communication. Cresskill, NJ: Hampton Press. 
Salem, P., Barclay, F., \& Hoffman, M. (2003, May). Organizational culture at the edge: A case study of organizational change. In Annual Meeting of the International Communication Association Meeting in San Diego, CA.

Sawyer, R. K. (2005). Social emergence: Societies as complex systems. Cambridge: Cambridge University Press.

Scott, W. R. (2002). Organizations: Rational, natural, and open systems (5th ed.). Englewood Cliffs, NJ: Prentice Hall.

Shannon, C. E., \& Weaver, W. (1949). The mathematical theory of communication. Urbana: University of Illinois Press.

Shaw, P. (2004). Changing conversations in organizations: A complexity approach to change. London: Routledge.

Shotter, J., \& Tsoukas, H. (2011). Complex thought, simple talk: An ecological approach to language-based change in organizations. In P. Allen, S. Maguire, \& B. McKelvey (Eds.), The Sage handbook of complexity and management (pp. 333-348). London: Sage.

Siira, K. (2013). Organizational conflict, conflict management, and communication: A social complexity perspective (Doctoral dissertation). Helsinki: Unigrafia.

Stacey, R. D. (1996). Complexity and creativity in organizations. San Francisco, CA: BerrettKoehler.

Stacey, R. D. (2001). Complex responsive processes in organizations. New York, NY: Routledge.

Stacey, R. D., Griffin, D., \& Shaw, P. (2000). Complexity and management: Fad or radical challenge to systems thinking? London: Routledge. 
Stephens, K. K., Harrison, J. R., Browning, L. D., Sornes, J., \& Saetre, A. S. (2007, Nov). The electronic garbage can. Paper presented at the annual meeting of the National Communication Association, Chicago, IL.

Stewart, P. (2001). Complexity theories, social theory, and the question of social complexity. Philosophy of the Social Sciences, 31(3), 323-360. http://dx.doi.org/10.1177/004839310103100303

Ströh, U. (2007). Relationships and participation: A complexity science approach to change communication. International Journal of Strategic Communication, 1(2), 123-137. http://dx.doi.org/10.1080/15531180701298916

Sundstrom, B., Briones, R. L., \& Janoske, M. (2013). Expecting the unexpected: Non-profit women's organizations' media responses to anti-abortion terrorism. Journal of Communication Management, 17(4), 341-363. http://dx.doi.org/10.1108/JCOM-082012-0069

Taylor, J. R., \& Van Every, E. J. (2000). The emergent organization: Communication as its site and surface. Mahwah, NJ: Erlbaum.

Thietart, R. A., \& Forgues, B. (2011). Complexity science and organization. In P. Allen, S. Maguire, \& B. McKelvey (Eds.), The Sage handbook of complexity and management (pp. 53-64). London: Sage.

Tsoukas, H., \& Hatch, M. J. (2001). Complex thinking, complex practice: The case for a narrative approach to organizational complexity. Human Relations, 54(8), 979-1013. http://dx.doi.org/10.1177/0018726701548001

Uddin, S., Hossain, L., Murshed, S. T., \& Crawford, J. W. (2011). Static versus dynamic topology of complex communications network during organizational crisis. Complexity, 16(5), 27-36. http://dx.doi.org/10.1002/cplx.20349 
van Uden, J., Richardson, K. A., \& Cilliers, P. (2001). Postmodernism revisited? Complexity science and the study of organisations. Tamara: Journal of Critical Postmodern Organization Science, 1(3), 53-68.

Walby, S. (2007). Complexity theory, systems theory, and multiple intersecting social inequalities. Philosophy of the Social Sciences, 37(4), 449-470. http://dx.doi.org/10.1177/0048393107307663

Weick, K. E. (1979). The social psychology of organizing (2nd ed.). Reading, MA: AddisonWesley.

Weick, K. E. (1995). Sensemaking in organizations. Thousand Oaks, CA: Sage. 
Table 1

Approaches to complexity in organizational and social research.

\begin{tabular}{lll}
\hline Objectivist & Interpretivist \\
\hline What is complexity? & Complexity is an objective property of & Complexity is a subjective \\
& real-world complex systems & $\begin{array}{l}\text { interpretation or a difficulty of } \\
\text { representing reality }\end{array}$
\end{tabular}

How we come to Through rigorous empirical

know about complex experiments and simulations phenomena?
What are the

Mathematical modeling, fitness

appropriate methods? landscape, agent-based simulations, qualitative methods
By providing rich interpretative accounts

Qualitative methods, actionresearch, language-based approaches
Strategies to deal with A "restrictive strategy" aims at complexity formulating appropriate "objective" explanations of complex phenomena
A "generalization strategy" tries to provide multiple and divergent explanations of the phenomenon at hand

Research aim Discover universal or contingent causal Provide contextual, interpretive laws narratives; descriptions; and qualitative explanations

Examples of research Modeling and simulating aspects of foci complex systems; theory building; theorizing organizational phenomena by complexity models
Using complexity theory as a metaphorical lens or inspiring constructs; studying experienced complexity 
Table 2

Perspectives on complexity in the field of organizational communication: five clusters (C1C5).

\begin{tabular}{|c|c|c|c|c|}
\hline \multicolumn{2}{|c|}{$\begin{array}{l}\text { ParadigmaticCluster } \\
\text { assumptions }\end{array}$} & \multicolumn{2}{|c|}{$\begin{array}{l}\text { Relationship withResearch foci } \\
\text { communication }\end{array}$} & \multirow{2}{*}{$\begin{array}{l}\text { Illustrative research } \\
\text { Contractor (1994); } \\
\text { Contractor and Grant } \\
\text { (1996); Monge and } \\
\text { Contractor (2003); } \\
\text { Uddin et al. (2010) }\end{array}$} \\
\hline Objectivist & $\begin{array}{l}\text { C1: Agent- } \\
\text { based models } \& \\
\text { network } \\
\text { analysis }\end{array}$ & $\begin{array}{l}\text { Networks of } \\
\text { communication } \\
\text { and information } \\
\text { diffusion }\end{array}$ & $\begin{array}{l}\text { Deduction of } \\
\text { hypotheses; data- and } \\
\text { model-driven theory- } \\
\text { building }\end{array}$ & \\
\hline & $\begin{array}{l}\text { C2: Network of } \\
\text { texts }\end{array}$ & $\begin{array}{l}\text { f Language or text } \\
\text { as a symbolic } \\
\text { representation; } \\
\text { semantic } \\
\text { linkages }\end{array}$ & $\begin{array}{l}\text { Analysis of large } \\
\text { quantities of text; } \\
\text { identification of } \\
\text { essential content and } \\
\text { words }\end{array}$ & $\begin{array}{l}\text { Corman et al. (2002); } \\
\text { Dooley et al. (2003) }\end{array}$ \\
\hline \multirow[t]{3}{*}{ Interpretivis } & $\begin{array}{l}\text { C3: Meaning } \\
\text { and } \\
\text { interpretation }\end{array}$ & $\begin{array}{l}\text { Negotiation and } \\
\text { exchange of } \\
\text { meaning }\end{array}$ & $\begin{array}{l}\text { Theory-development; } \\
\text { conceptualization of } \\
\text { communication }\end{array}$ & $\begin{array}{l}\text { Aula }(1996,1999, \\
\text { 2000); Salem (2002, } \\
\text { 2009); Sundstrom et al. } \\
\text { (2013) }\end{array}$ \\
\hline & $\begin{array}{l}\mathrm{C} 4 \text { : Narratives } \\
\text { and language }\end{array}$ & $\begin{array}{l}\text { Narratives; } \\
\text { discourse }\end{array}$ & $\begin{array}{l}\text { Contextualized and } \\
\text { emergent discourse; } \\
\text { complexity of } \\
\text { conversation; argument } \\
\text { as a chaotic system }\end{array}$ & $\begin{array}{l}\text { Luhman and Boje } \\
\text { (2001); Tsoukas and } \\
\text { Hatch (2001); Hawes } \\
\text { (1999); Leeuwis and } \\
\text { Aarts (2011); Isbell } \\
\text { (2009); Bloom (2001) }\end{array}$ \\
\hline & $\begin{array}{l}\text { C5: Living } \\
\text { activity }\end{array}$ & \multicolumn{2}{|c|}{$\begin{array}{ll}\text { Relational action; } & \text { Relational uniqueness } \\
\text { collective sense } & \text { and emergent change; } \\
\text { making; complex embodied/situational } \\
\text { responsive } & \text { sense making; } \\
\text { processes } & \text { organization- } \\
& \text { communication } \\
& \text { relationship }\end{array}$} & $\begin{array}{l}\text { Shotter and Tsoukas } \\
\text { (2011); Hoffman (2008); } \\
\text { Stacey (2001); } \\
\text { Kristiansen (2013) }\end{array}$ \\
\hline
\end{tabular}




\section{Footnotes}

${ }^{i}$ This practice must be distinguished, however, from the simple scientific model assuming that we can wholly describe and predict the behaviors of a system by knowing the laws governing its behaviors. Rather, this version of complexity denies predicting the behaviors of a system in this way and delimits its explanations to rules defining only the range of actions of the components in the system (Byrne, 2005, p. 102).

${ }^{\text {ii }}$ See special issue of E:CO, Complexity and Storytelling, 7(3-4), 2005.

iii This is important to note, since analogies may have important heuristic and didactic value, but they do not, of course, have explanatory power, as such, outside of the original context (Hempel, 1977, p. 253). 